Research papers

\title{
Model uncertainty reduction for real-time flood control by means of a flexible data assimilation approach and reduced conceptual models
}

\author{
E. Vermuyten*, P. Meert, V. Wolfs, P. Willems \\ KU Leuven, Department of Civil Engineering, Hydraulics Section, Kasteelpark Arenberg 40, BE-3001, Belgium
}

\section{A R T I C L E I N F O}

This manuscript was handled by Emmanouil Anagnostou, Editor-in-Chief, with the assistance of Viviana Maggioni, Associate Editor

Keywords:

Real-time flood control

Model predictive control

Reduced genetic algorithm

Hydrodynamic model uncertainty

Data assimilation

\begin{abstract}
A B S T R A C T
Recently, a combination of model predictive control and a reduced genetic algorithm (RGA-MPC) has shown to be an efficient control technique for real-time flood control, making use of fast conceptual river models. This technique was so far only tested under ideal circumstances of perfect model predictions. Prediction errors originating from hydrodynamic model mismatches, however, result in a deterioration of the real-time control performance. Therefore, this paper presents two extensions of the RGA-MPC technique. First, a new type of conceptual model is introduced to further increase the computational efficiency. This reduced conceptual model is specially tailored for real-time flood control applications by eliminating all unnecessary intermediate calculations to obtain the flood control objectives and by introducing a new transport element by means of flow matrices. Furthermore, the RGA-MPC technique is extended with a flexible data assimilation approach that analyzes the past observed errors and applies an appropriate error prediction scheme. The proposed approach largely compensates for the loss in control performance due to the hydrodynamic model uncertainty.
\end{abstract}

\section{Introduction}

The number of river floods has steadily increased during the last decades, as well in Belgium (MIRA, 2013) as in other parts of the world (EM-DAT, MEA, 2005). Increasing trends of extreme rainfall events due to climate change (Lehner et al., 2006, Willems et al., 2012, IPCC, 2014, Vansteenkiste et al., 2014) and the rising urbanization (Huang et al., 2008, Hawley and Bledsoe, 2011, Poelmans et al., 2011) are two examples of ongoing trends that are associated with increasing number of floods. Previous research has shown that these economically costly natural disasters can be strongly reduced by using model predictive control (MPC) for improved retention basin management (BarjasBlanco et al., 2010, Breckpot et al., 2013, Chiang and Willems, 2015). The MPC technique aims to optimize the retention basin regulation, e.g. the controllable gate levels, in real-time making use of rainfall forecasts and model-based predictions of river flow conditions, based on a given objective. Several successful applications of MPC for improved reservoir operation can be found in the literature (e.g. Galelli et al., 2014, Schwanenberg et al., 2014, Tian et al., 2015, Ficchi et al., 2016).

Recently, a combination of MPC and a reduced genetic algorithm (RGA) was presented as a successful and fast alternative for classic MPC controllers (Vermuyten et al,. 2018). RGA-MPC uses fast conceptual river models (Wolfs et al., 2015) to predict the future system states. For the Demer basin in Belgium, damage cost reductions between $2 \%$ and $31 \%$ were obtained with this heuristic approach in comparison to the current regulation based on programmable logic controllers (PLC). RGA-MPC was so far only tested under ideal circumstances of assumed perfect model predictions, while model mismatches and rainfall forecast errors can have an important impact on the control performance (Walker et al., 2003, Brandimarte and Di Baldassarre, 2012).

Model-based flood forecast uncertainty may originate from four key uncertainty sources: model input, observational, model parameters and model structure uncertainties (Refsgaard et al., 2007, Shrestha and Solomatine, 2008, Freni and Mannina, 2010, Willems, 2012). In this paper, the uncertainties related to the hydrodynamic river model components are addressed. They result in deviations between the predictions used in the MPC based optimization process and the actual river system observations and, as a consequence, lead to a loss in flood control performance.

MPC has some 'inherent robustness' towards uncertainties due to its receding horizon strategy (De Nicolao et al., 1996, Magni and Sepulchre, 1997, Mayne et al., 2000). This inherent robustness is, however, limited and the impact of large uncertainties will be unacceptable. Therefore, an efficient real-time control system should consist of efficient model-updating algorithms and uncertainty propagation techniques, beside an efficient optimization algorithm (Sarma

\footnotetext{
* Corresponding author.

E-mail addresses: evert.vermuyten@kuleuven.be (E. Vermuyten), pieter.meert@kuleuven.be (P. Meert), vincent.wolfs@kuleuven.be (V. Wolfs), patrick.willems@kuleuven.be (P. Willems).
} 
et al., 2006). Data assimilation methods update the river model and systematically eliminate the deviations between predictions and observations (Hutton et al., 2011,a,b, Liu et al., 2012). In order to include the input uncertainty, robust MPC controllers such as multiple MPC (van Overloop et al., 2008), adaptive multiple MPC (Delgoda et al., 2013) and tree-based MPC (Raso et al., 2014) have been developed.

Two groups of data assimilations methods are typically considered to account for the hydrodynamic model uncertainty: state updating by means of state estimators (SE) and error correction by means of prediction error methods (PEM). State estimators, such as a moving horizon estimator (Haseltine and Rawlings, 2005, Rawlings and Bakshi, 2006, Liu et al., 2012) or an ensemble Kalman filter (Evensen, 1994), adjust the initial conditions of the river model to match the observations. This model updating approach improves the initial conditions of the prediction model and thus also the prediction accuracy. The effect of this update will, however, wash out with increasing lead time as no observations are yet available for this forecast period (Madsen and Skotner, 2005). Prediction error methods analyze the past model residuals and apply an error correction scheme to improve the prediction accuracy. Few examples are autoregressive, moving-average and autoregressive-moving-average models (Broersen and Weerts, 2005, Liu et al., 2012). This paper analyzes the performance of different state estimators and predictions error methods and their applicability in combination with conceptual models and RGA-MPC. A new flexible data assimilation approach is presented and compared against existing data assimilation methods.

\section{Study area}

The Demer basin is a very flood prone area located in the eastern part of Flanders, Belgium. During the last decades, this basin has faced many floods of which the floods of September 1998, January 2002 and November 2010 are the most extreme ones. For example, the severe flood of September 1998, which has an approximate return period of 100 years, caused a total loss of 16 million EUR (HIC, 2003).

This densely populated basin covers a total area of $2334 \mathrm{~km}^{2}$, mostly consisting of loam and sand. The main stream is the Demer river which has its source in Ketsingen at an altitude of $89 \mathrm{~m}$ above the Belgian reference level TAW and flows after $85 \mathrm{~km}$ into the Dijle river in Werchter at $10 \mathrm{~m}$ TAW. The Demer river and its most important tributaries (Herk, Velpe and Gete) are fed by a spring. Nevertheless, these rivers can be seen as rain-fed rivers due to their high sensitivity to rainfall. For example, the average downstream discharge of the Demer river is $6 \mathrm{~m}^{3} / \mathrm{s}$ in summer (August) and $34 \mathrm{~m}^{3} / \mathrm{s}$ in winter (December). The catchments average annual rainfall is $800 \mathrm{~mm}$.

This paper focuses on the Herk river system, which is part of the Demer basin. The Herk case study consists of two streams: Kleine Herk in the north and Grote Herk in the south (Fig. 1). An inline retention basin was installed in 2014 to protect the city of Stevoort. Three hydraulic structures regulate the water flow in this network. For this river, a full hydrodynamic model based on detailed cross-section data and including the main floodplains, retention basin and hydraulic structures has been implemented and calibrated before by the Flemish Environment Agency (VMM). This model was implemented in the InfoWorks RS software.

\section{Methods}

\subsection{Conceptual modelling}

The river models used in this research are conceptual models created semi-automatically by means of the Conceptual Model Developer (CMD) tool of Wolfs et al. (2015). This flexible and modular conceptual modelling approach divides the entire river network into distinct units to simplify the network topology (storage cell concept). The resulting reservoir models are less detailed than full hydrodynamic river models,

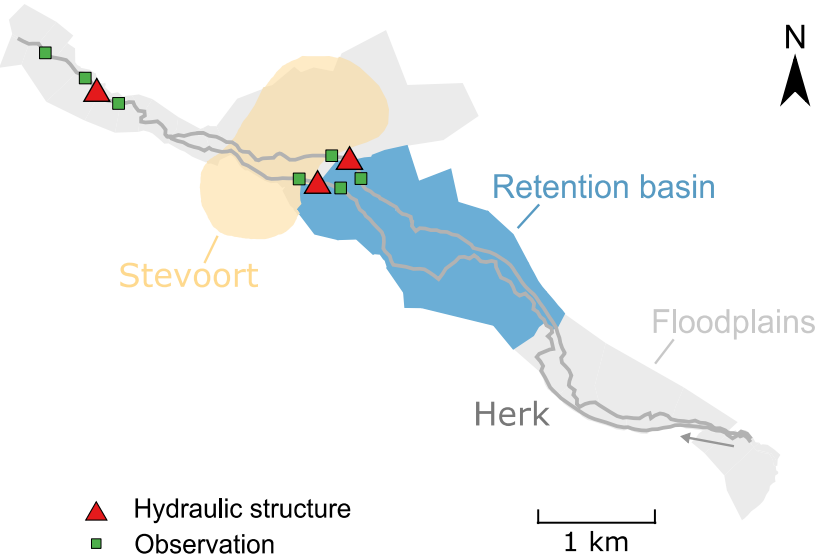

Fig. 1. River network of the Herk case study, together with the retention basin, the hydraulic structures, observation locations and the city of Stevoort.

but computationally much more efficient. As only a limited number of observations are available along river networks, simulation results with full hydrodynamic models are used to calibrate conceptual models (Meirlaen et al., 2001, Vanrolleghem et al., 2005). These conceptual models have been successfully applied for flood modelling, integrated catchment modelling and recently for real-time flood control (Wolfs et al., 2012, De Vleeschauwer et al., 2014, Wolfs et al., 2016, Meert et al., 2016, Vermuyten et al., 2018).

A standard conceptual model consists of different reservoirs interconnected by hydraulic structures. The volume in each reservoir is calculated by means of a mass balance equation based on the incoming and outgoing flows. These volumes are transformed to water levels located in the reservoirs using hypsometric curves. The flows over the hydraulic structures and the different control objectives are calculated based on these water levels (Fig. 2, left). Rainfall-runoff discharges originating from synthetic hydrographs or hydrological models are the inputs to the conceptual models.

Fig. 3 gives an overview of three conceptual model types. In a detailed conceptual model, each floodplain area of the full hydrodynamic model (InfoWorks RS) is explicitly modeled as a distinct reservoir. This conceptual model type has the best model accuracy and is computationally much more efficient than the full hydrodynamic model. As evolutionary optimization methods such as RGA require many iterations, Vermuyten et al. (2018) developed a simplified conceptual model to further improve the computational efficiency. This approach integrates floodplain areas in river reservoirs where possible or merges them with each other, while making a tradeoff between model accuracy and computational efficiency.

This paper presents a revised conceptual model type, the reduced conceptual model. It is based on an approach that further increases the computational efficiency by eliminating unnecessary variables and intermediate calculations to obtain the flood control objectives and thus reducing the number of calculation nodes. As the control objectives are uniquely related to the water levels and these water levels are unambiguously related to the reservoir volume, the control objectives can be directly calculated based on the reservoir volume and aggregated per reservoir (Fig. 2). Furthermore, also the hydraulic structure equations are eliminated from the model. These equations are taken the same as the ones implemented in the full hydrodynamic InfoWorks RS software (Innovyze, 2014) and their application is computationally demanding. Therefore, all hydraulic structures between two reservoirs are grouped and replaced by a new transport element, a flow matrix. The resulting flow between the two reservoirs is calculated in a preprocessing step for different combinations of the reservoir volumes and stored in these multidimensional lookup tables. The volume of each reservoir is varied based on a fixed water level step of the reservoirs representative water level. This representative water level is the only water level per 

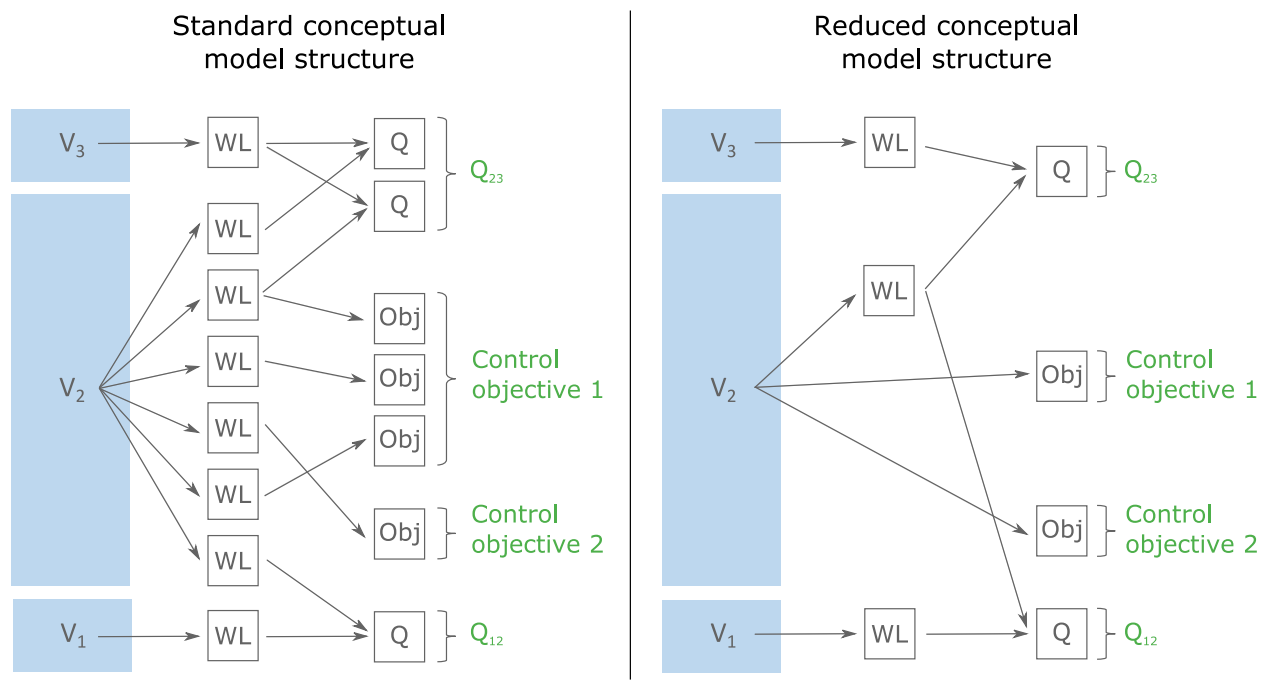

Fig. 2. Illustration of the model reduction approach. Control objectives are directly calculated based on the reservoir volume. Hydraulic structures are grouped and replaced by flow matrices.

InfoWorks RS

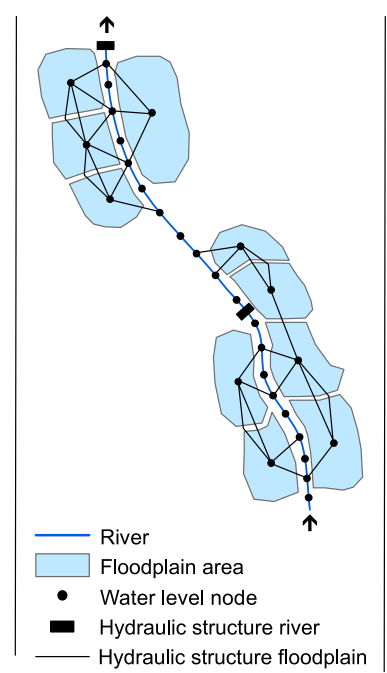

Detailed CM

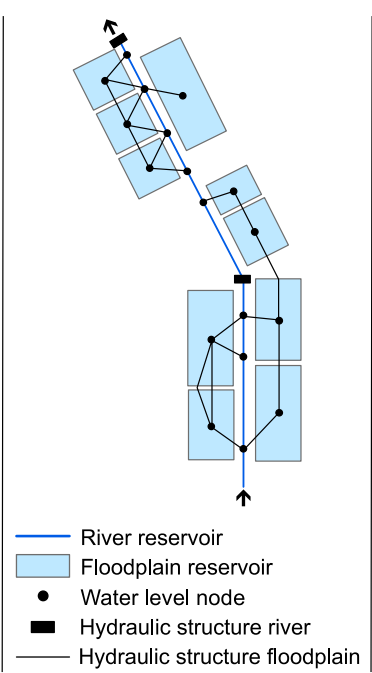

Simplified CM

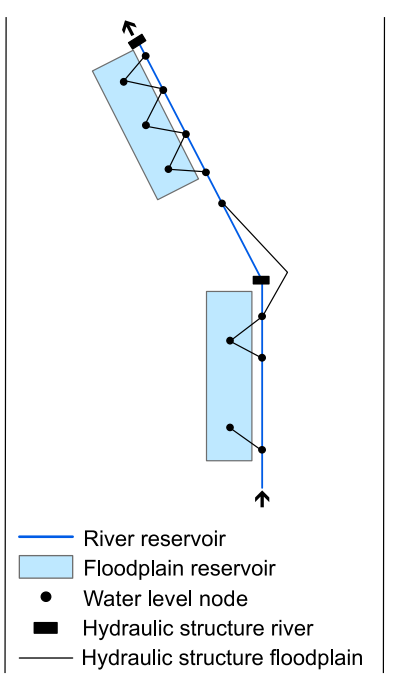

Reduced CM

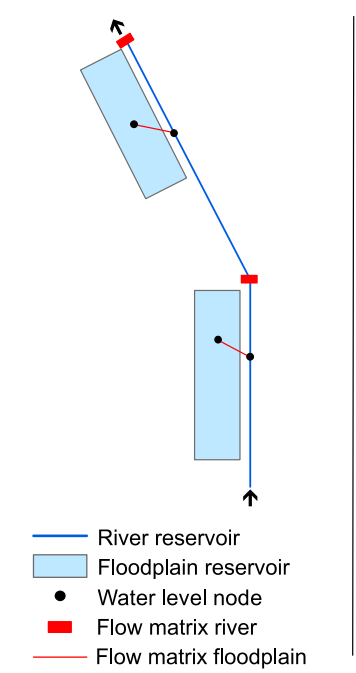

Fig. 3. Hypothetical examples of three different conceptual model types derived from a detailed InfoWorks RS model.

reservoir that is modelled and serves as an input for the flow matrix calculations. The water level step is set to $1 \mathrm{~cm}$ for the Herk case study, but can also be taken different per reservoir. For each controllable hydraulic structure between the two reservoirs, the gate level of this structure is added as an additional dimension of the flow matrix. Gate levels are varied with $1 \mathrm{~cm}$ between the upper and lower boundary of the gate position. An example of a two-dimensional flow matrix is given in Fig. 4.

\subsection{Model predictive control and reduced genetic algorithm}

RGA-MPC is a technique that combines model predictive control (MPC) based on a fast conceptual river model and a reduced genetic algorithm (RGA). Applied to our case, the technique optimizes the gate positions in real-time based on the conceptual model predictions of future river flows and minimization of the total flood damage within a given time horizon as objective function. In here, the RGA is an heuristic optimization method that strongly reduces the number of possible solutions by considering only a subset of the possible gate operation positions at future time moments as optimization variables. Each optimization starts with an update of the initial conditions of the prediction model in order to represent the current actual system states. Next, possible future control strategies are generated, so-called gate level (GL) scenarios. This generation can be random or the best control strategy so far can be mutated. Next, the newly generated control strategy is applied to the river model and the results are compared with those of the best solution so far. The best control strategy with respect to the objective criteria is selected to be used during the next iteration until the stopping criteria are being met. The reduced genetic algorithm has a higher convergence rate than a standard genetic algorithm. For more details about the RGA-MPC method, the reader is referred to Vermuyten et al., (2018).

\subsection{Hydrodynamic model uncertainty}

This study considers three types of models to simulate the river hydrodynamics: the full hydrodynamic model implemented in InfoWorks RS, the original detailed conceptual model and the reduced conceptual model. In order to investigate the effect of the hydrodynamic model uncertainty on the prediction accuracy and the real- 
Total flow from reservoir 1 to reservoir 2

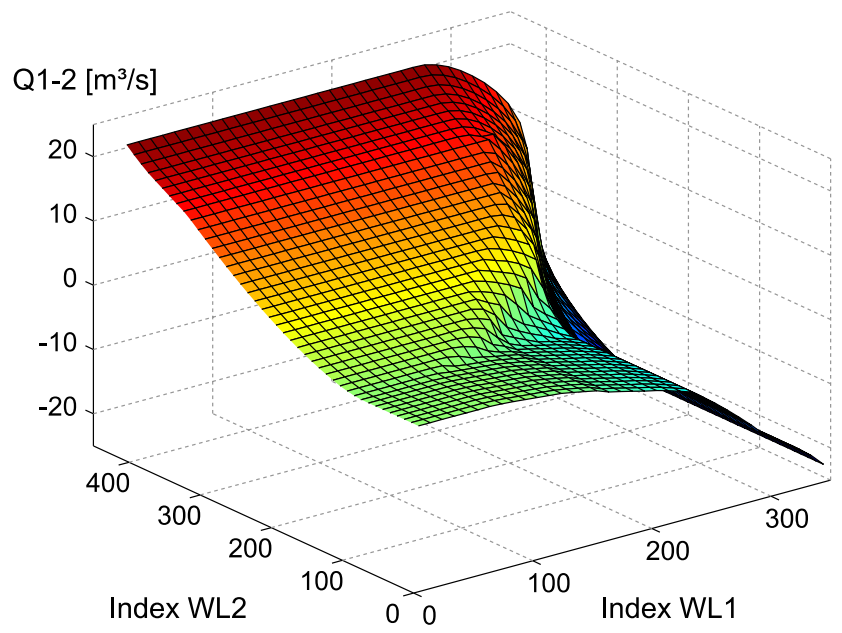

Fig. 4. Two-dimensional flow matrix to calculate the total flow between two reservoirs, based on the representative water level (WL) of each reservoir.

time control performance, a different model is used to represent the actual river system (simulation model) and to predict the future system states (prediction model). The detailed conceptual model is assumed here as a close representation of the actual river system and serves as simulation model. The reduced conceptual model is subject to model mismatches towards the detailed conceptual model as a result of the simplification and reduction processes to increase the computational efficiency of the river model, see section 3.1. The differences between the reduced and the detailed conceptual model are in this study considered as the hydrodynamic model uncertainty by using the reduced conceptual model as prediction model. It has to be noted that this model uncertainty is likely to be smaller than the differences one would obtain if the reduced conceptual model results would be compared with observations (Meert, 2017). The aim of this experimental set-up is, however, to isolate and investigate the importance of the hydrodynamic model uncertainty and the added value of an eventual data-based postbias correction of the model by means of data assimilation. All considered data assimilation methods are applied to the reduced conceptual model (prediction model) in order to match the detailed conceptual model (simulation model).

\subsection{Data assimilation}

Due to the hydrodynamic model uncertainty, the state predictions by the model may drift away from the actual system states if no feedback mechanism by means of data assimilation is introduced. A good data assimilation approach consists of an update of the initial conditions of the prediction model (state estimator) and an error correction of the forecast simulation (prediction error method). Fig. 5 shows the flowchart of the reduced genetic algorithm with data assimilation.

Data assimilation relies on observations along the river network, which are only available at a limited number of locations. For example, only seven out of the twelve reservoirs in the reduced conceptual model of the Herk river have a water level observation available. State estimators can, however, estimate all system states based on only few observations in order to obtain good initial conditions for all reservoirs. Prediction error methods (PEM) analyze the model residuals of the hindcast simulation, predict the forecast error and impose this error correction on the forecast simulation in a post-processing step. The error at the time of forecast (TOF) is usually reduced to zero in this way.

The next two sections describe different state estimators and prediction error methods. All considered data assimilation methods correct

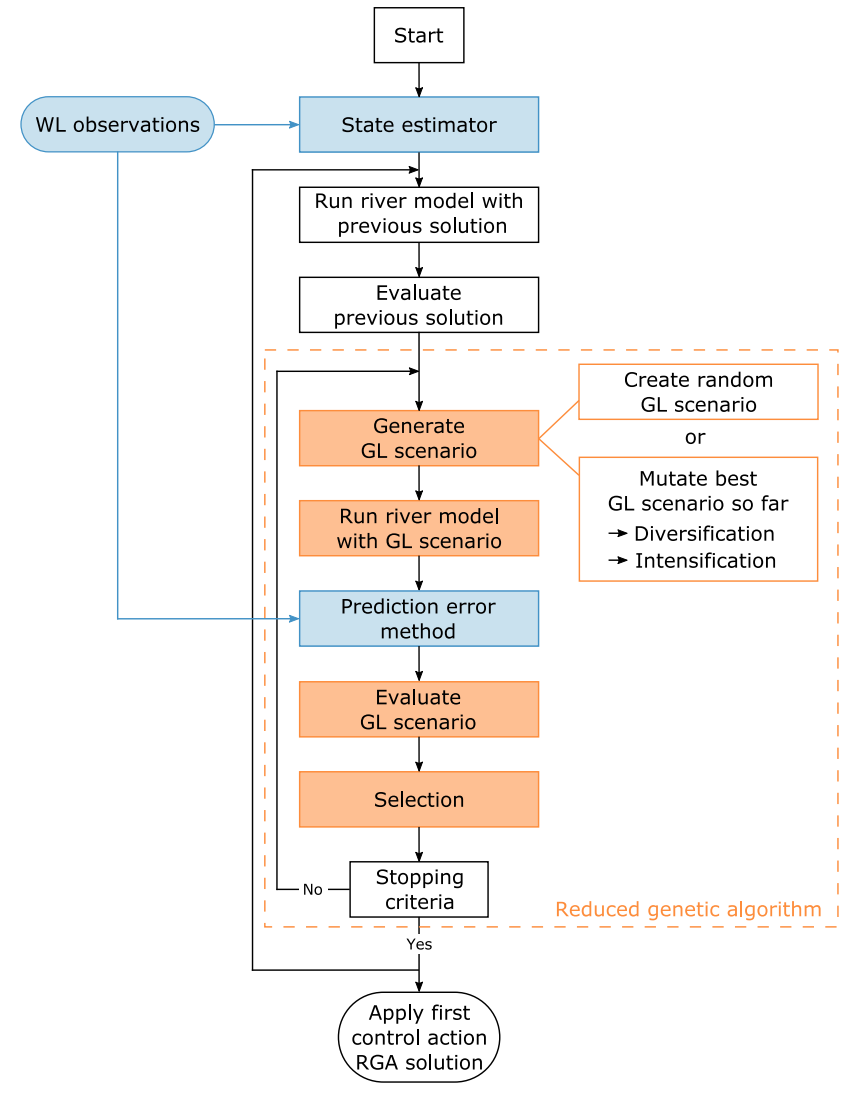

Fig. 5. Flowchart of the reduced genetic algorithm with data assimilation (blue). (For interpretation of the references to color in this figure legend, the reader is referred to the web version of this article.)

the states of the prediction model, i.e. the reservoir volumes, based on the observed water level deviations. First, the water level predictions at observed locations are corrected, after which the volumes of the corresponding reservoirs are adjusted accordingly by means of the water level - volume relations of the reservoirs (the hypsometric curves). In this way, all other water levels and the control objectives, which are calculated based on these volumes, are also corrected and the feedback is taken into account during the optimization.

\subsection{State estimators}

\subsubsection{Instant updating}

Instant or instantaneous updating (IU) is a very simple and fast state estimator that makes use of the characteristics of the conceptual reservoir model. Reservoirs that cover an observation location are instantaneously updated, based on the real-time water level observations. The observed water level is converted to the reservoir state (volume), making use of the reservoir hypsometric curve. If two or more observation locations are available along the region covered by the same reservoir, the most representative observation location for the reservoir is considered on the basis of the updating. Reservoirs without observations are not updated, which is the main drawback of instant updating.

\subsubsection{Total instant updating}

Total instant updating (TIU) is a rather theoretical state estimator, similar to instant updating. TIU assumes that each reservoir has an observation available. In practice, this will seldom be the case, as observations are typically only available in river reaches and mostly at controlled hydraulic structures. This experimental state estimator may, however, give an indication of the added value of installing additional 
measurement devices. Each reservoir is updated in the same way as with instant updating.

\subsubsection{Moving horizon estimator}

A moving horizon estimator (MHE) updates the initial model states by modifying the historical inputs, states or model parameters (Haseltine and Rawlings, 2005, Rawlings and Bakshi, 2006, Liu et al., 2012). This is achieved by solving an online optimization problem in which the simulation results for the hindcast period are fitted to the observation data. The squared error objective for this optimization problem is formulated as follows:

$J=\sum_{i} w_{y}\left(x_{i}-y_{i}\right)^{2}+\sum_{i} w_{\hat{x}}\left(x_{i}-\widehat{x}_{i}\right)^{2}+\sum_{i} w_{p_{i}} \Delta p_{i}^{2}$

with $\mathrm{J}$ the optimization cost function over the hindcast period, $\mathrm{x}_{\mathrm{i}}$ the $\mathrm{i}$-th predicted variable, $\mathrm{y}_{\mathrm{i}}$ the $\mathrm{i}$-th observed variable, $\hat{x}_{i}$ the $\mathrm{i}$-th prior predicted variable, $\mathrm{p}_{\mathrm{i}}$ the $\mathrm{i}$-th estimated parameter, input or state variable and $w_{y}, w_{\hat{x}}$ and $w_{p_{i}}$ the weighting coefficients for the different cost terms. The first cost term resembles the penalty cost for residuals towards observations, the second for residuals towards prior model predictions and the third for changes in the estimated parameters, inputs or state variables.

In this study, the states at the beginning of the hindcast period are being optimized with the MHE. Reservoirs with an observation available are updated by means of instant updating, while reservoirs without observation are sequentially optimized based on the cost function $\mathrm{J}$. The last estimated state variables from the hindcast simulation are used as initial conditions for the prediction model.

As a MHE in turns involves optimization, the main drawback of this approach is the computational complexity (Haseltine and Rawlings, 2005, Rawlings and Bakshi, 2006). Conceptual models, however, provide a solution here due to their high computational efficiency.

\subsubsection{Ensemble Kalman filter}

The Kalman filter is assumed to be the optimal state estimator for unconstrained, linear systems (Haseltine and Rawlings, 2005, Rawlings and Bakshi, 2006). For nonlinear systems, the extended Kalman filter was developed, which first linearizes the nonlinear system before applying the Kalman filter. The extended Kalman filter is, however, difficult to implement and to tune and not reliable for highly nonlinear systems such as flood forecasting models (Julier and Uhlmann, 2004). To overcome this problem, the ensemble Kalman filter (EnKF) was introduced by Evensen (1994). An EnKF is actually a Monte Carlo approach in which an ensemble of model states is propagated based on perturbed input series (Hutton et al., 2014b). The EnKF has been extensively applied in different disciplines due to its easy implementation and general applicability to any reservoir model (Naevdal et al., 2003, Hargreaves et al., 2004, Wen and Chen, 2005, Xie and Zhang, 2010). It is basically a recursive filter that minimizes the covariance of prediction errors and consists of two steps: a prediction step and an analysis step. The prediction step creates rainfall-runoff input ensembles by adding noise to the deterministic rainfall-runoff input series. These ensembles are then applied to the conceptual river model which generates model predictions for each of these ensembles. The analysis step creates observation ensembles and calculates the error covariance matrices and the Kalman gain. The state ensembles are then updated based on the linear correction of the standard Kalman Filter. For the more details about the approach, see e.g. Evensen, 1994, Moradkhani et al., 2005, Gillijns et al., 2006, Komma et al., 2008, Chen et al., 2011.

\subsection{Prediction error methods}

\subsubsection{Prediction error models Van Steenbergen}

Van Steenbergen et al. (2013) proposed six prediction error models (PEM) to reduce the prediction error of river catchment hydrological models. These predefined error models analyze the error during the hindcast period and predict the error during the forecast period. The original forecast simulation is then corrected by applying this error correction in a post-processing step. This approach can also be applied to correct flood predictions, based on water level observations. An overview of the six prediction error models is given below.

PEM1:

$e(t)=e_{1}$

PEM2:

$e(t)=e_{1}+\frac{e_{m}-e_{1}}{t_{n}-t_{1}}\left(t-t_{1}\right)$

PEM3:

$e(t)=e_{1} * a_{m}{ }^{\left(t-t_{1}+1\right)}$

PEM4:

$e(t)=e_{1} * a_{m}{ }^{\left(t-t_{1}+1\right)}+\left(1-a_{m}{ }^{\left(t-t_{1}+1\right)}\right) * e_{m}$

PEM5:

$e(t)=e_{1} * a_{t}^{\left(t-t_{1}+1\right)}+\left(1-a_{t}^{\left(t-t_{1}+1\right)}\right) * e_{m}$

PEM6

$e(t)=\frac{e_{1} *\left(t_{n}-t\right)+e_{1} * a_{m}{ }^{\left(t-t_{1}+1\right)}\left(t-t_{1}\right)}{\left(t_{n}-t\right)+\left(t-t_{1}\right)}$

with $\mathrm{e}_{1}$ the error at the time of forecast, $\mathrm{e}_{\mathrm{m}}$ the mean hindcast error, $t_{1}$ the time of forecast, $t_{n}$ the forecast period, $a_{m}$ the mean correlation factor and $a_{t}$ the correlation factor at time $t$.

\subsubsection{Autoregressive-moving-average model}

The autoregressive-moving-average (ARMA) model was introduced by Whittle (1951) and combines the autoregressive model and the moving-average model. Both models predict the future values of a time series after analyzing the given time series. The autoregressive model is based on a linear combination of the past values, while the movingaverage model is based on a linear combination of past error terms. The ARMA model contains both models and can be formulated as follows, with $\mathrm{p}$ autoregressive terms and q moving-average terms:

$x_{t}=c+\varepsilon_{t}+\sum_{i=1}^{p} a_{i} x_{t-i}+\sum_{i=1}^{q} b_{i} \varepsilon_{t-i}$

with $\mathrm{x}$ time series values, $\mathrm{c}$ a constant, $\varepsilon$ white noise error terms, $\mathrm{a}_{\mathrm{i}}$ parameters of the autoregressive model and $b_{i}$ parameters of the moving-average model.

This study makes use of the ARMASA toolbox developed by Broersen (2002) to determine the optimal ARMA model. This automatic algorithm computes several autoregressive, moving-average and ARMA candidate models based on the hindcast residuals and selects the best model to correct the forecast simulation.

\subsubsection{Error matrix and error vector}

The error matrix approach analyzes the hindcast residuals and stores them in a matrix as a function of the lead time and the water level. Newly calculated errors are averaged towards the previous error value stored in the matrix. The final result is a forecast error correction as a function of the lead time and the water level. Water levels are divided into classes of $5 \mathrm{~cm}$ and lead times into classes of $15 \mathrm{~min}$. The hindcast period has to be equal to the forecast period in this approach.

Alternatively, the error values can be stored in an error vector, only depending on the water level. In this way, feedback from the hindcast period can be taken into account more rapidly during the forecast correction and the hindcast period can be taken shorter than the forecast period. The dependency on the lead time is, however, no longer taken into account. Newly calculated errors are again averaged towards the previously stored error value. 
Table 1

Description of the condition and the corresponding prediction error model for the four scenarios of the flexible prediction error method.

\begin{tabular}{|c|c|}
\hline Condition & Prediction error model \\
\hline Difference between maximum and minimum hindcast error $<1 \mathrm{~cm}$ & $\begin{array}{l}\text { Linear interpolation between } e_{1} \text { at the time of forecast (TOF) and zero at the end of the } \\
\text { forecast period }\end{array}$ \\
\hline Monotonically increasing trend of the absolute hindcast error & $\begin{array}{l}\text { Spline fitted through the hindcast errors and zero at the two last points of the forecast } \\
\text { period }\end{array}$ \\
\hline Monotonically decreasing trend of the absolute hindcast error & $\begin{array}{l}\text { Linear extrapolation of the two last hindcast errors until a forecast error correction of } \\
\text { zero is reached, zero afterwards }\end{array}$ \\
\hline Other situations & $\begin{array}{l}\text { Linear interpolation between } e_{1} \text { at the time of forecast (TOF) and zero at the end of the } \\
\text { forecast period }\end{array}$ \\
\hline
\end{tabular}

\subsubsection{Flexible prediction error method}

After analyzing several historical hindcast simulations, four hindcast scenarios are defined. The first hindcast scenario corresponds to an almost constant error over the hindcast period. The threshold for this scenario was set to $1 \mathrm{~cm}$ difference between the maximum and minimum hindcast error. The two most important hindcast scenarios are a monotonically increasing and monotonically decreasing trend. All hindcast simulations without a clear trend are categorized under the fourth hindcast scenario. For each of the four hindcast scenarios, the corresponding historical forecast errors are analyzed and an appropriate prediction error model (PEM) is determined. Table 1 gives an overview of the four hindcast scenarios and the corresponding PEM in order of priority. Fig. 6 shows an illustrative example of the error correction for each of the four scenarios.

The flexible prediction error method (Flex PEM) analyzes the observed hindcast errors and automatically selects one of the four hindcast scenarios. The PEM corresponding to the selected scenario is applied to the forecast simulation. When combining Flex PEM with a state estimator, this state estimator is applied to the first time step of the hindcast simulation. The hindcast results corresponding to the time of forecast are used as initial conditions for the forecast model. In this way, forecast errors can be estimated as the observed error trend during the hindcast period, i.e. after the state estimation, will continue during the forecast period.

\subsection{Real-time control performance}

RGA-MPC optimizes the future control strategy based on the output of the prediction model. Due to model uncertainties, these predictions

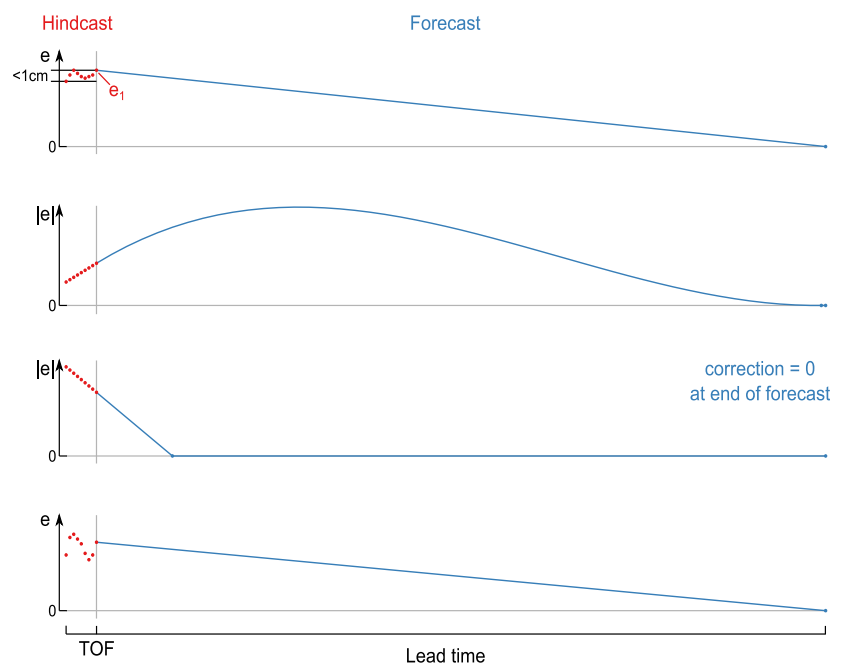

Fig. 6. Example of the prediction error model for each of the four scenarios of the flexible prediction error method.
Table 2

Overview of the three different types of MPC to investigate the effect of data assimilation on the real-time control performance when considering model uncertainty.

\begin{tabular}{llll}
\hline MPC & Simulation model & Prediction model & Model uncertainty \\
\hline No DA & Detailed CM & Reduced CM & Yes \\
MPC DA & Detailed CM & Reduced CM & Yes \\
Ideal MPC & Detailed CM & Detailed CM & No \\
\hline
\end{tabular}

will deviate from the actual future observations in the simulation model and the real-time controller may take wrong anticipating actions. Three different types of MPC are considered to investigate how a feedback mechanism by means of data assimilation (DA) can reduce the loss in control performance due to model uncertainties (Table 2).

All three MPC types use the detailed conceptual model as reference simulation model in order to compare the control performance in an objective way. Ideal MPC considers no model uncertainty as the detailed conceptual model is also used as prediction model. This means that the controller has perfect knowledge about the future system states. Ideal MPC is used as a benchmark in this study as it represents the best obtainable solution. On the other hand, no DA is used as a second benchmark as it represents an MPC optimization without feedback from observations. For this, model uncertainty is introduced by using the reduced conceptual model as prediction model. MPC DA, finally, represents an MPC optimization in which data assimilation methods are implemented to reduce the performance loss due to model uncertainties. Again, model uncertainty is introduced by using the reduced conceptual model as prediction model.

Several data assimilation methods are tested in combination with MPC to investigate their effect on the real-time control performance. This performance is compared against the two benchmarks, ideal MPC and no DA, with the following formula, based on the total damage costs of the MPC optimizations:

$P I=\frac{\left(D_{\text {no DA }}-D_{M P C D A}\right)}{\left(D_{\text {no DA }}-D_{\text {ideal } M P C}\right)} * 100$

with PI the performance improvement [\%] and D the total damage cost $[€]$ (Vermuyten et al., 2018). A good MPC DA method will have a performance between that of ideal MPC and no DA, aiming for a performance close to ideal MPC or $100 \%$.

\section{Results}

\subsection{Conceptual models}

The conceptual models of the Herk are calibrated and validated based on the simulation results of the full hydrodynamic InfoWorks RS model. A brief description of the ten calibration and validation events is given in Table 3, together with the maximum total rainfall-runoff peak discharge. 
Table 3

Overview of the ten calibration and validation events with total rainfall-runoff peak discharges for the Herk case study.

\begin{tabular}{|c|c|c|c|}
\hline Event & Period & Description & $\begin{array}{l}\text { Total rainfall-runoff } \\
\text { peak discharge }\left[\mathrm{m}^{3} / \mathrm{s}\right]\end{array}$ \\
\hline E1 & Sept 1998 & Historical period of heavy rainfall & 46 \\
\hline $\mathrm{E} 2$ & Aug 2003 & Historical period of drought, followed by a small rainfall event & 25 \\
\hline E3 & Dec 1999-Jan 2000 & Historical period of heavy rainfall & 30 \\
\hline E4 & Jan-Feb 1995 & Historical period of heavy rainfall & 27 \\
\hline E5 & Jan-Feb 2002 & Historical period of heavy rainfall & 30 \\
\hline E6 & Nov 2010 & Historical period of heavy rainfall & 35 \\
\hline E7 & Synthetic hydrograph VMM & Synthetic hydrograph starting with a very dry period, followed by a heavy rainfall event, developed by VMM & 42 \\
\hline E8 & Synthetic hydrograph T1000 & Synthetic hydrograph with a return period of 1000 year, developed by VMM & 74 \\
\hline E9 & Sept $1998 \times 1.3$ & Artificial period of heavy rainfall, created by multiplying the historical period of Sept 1998 with a factor of 1.3 & 93 \\
\hline E10 & $2 \times$ Sept 1998 & Artificial period of heavy rainfall, created by duplicating the historical event of Sept 1998 in time & 62 \\
\hline
\end{tabular}

Table 4

Comparison of three conceptual model (CM) types with respect to model complexity, computational efficiency and model accuracy.

\begin{tabular}{|c|c|c|c|c|}
\hline & InfoWorks RS & Detailed CM & Simplified CM & Reduced CM \\
\hline WL nodes & $>550$ & 154 & 82 & 17 \\
\hline Hydraulic structures & $>200$ & 154 & 59 & 17 \\
\hline Time step & $100 s$ & $30 \mathrm{~s}$ & $300 \mathrm{~s}$ & $300 \mathrm{~s}$ \\
\hline Computation time & $1 \mathrm{~h}^{* * *}$ & $0.8 \mathrm{~s}$ & $0.025 \mathrm{~s}$ & $0.0025 \mathrm{~s}$ \\
\hline MAE & / & $5 \mathrm{~cm}$ & $10 \mathrm{~cm}$ & $10 \mathrm{~cm}$ \\
\hline
\end{tabular}

* Event E1 (28 days), Single Intel Xeon E5-1650 3.5 GHz PC with 32 GB RAM.

** Computation time for the complete Herk model in InfoWorks RS.

Table 4 gives an overview of the different conceptual model types with respect to model complexity, computational efficiency and model accuracy. In general, conceptual models strongly reduce the number of calculation nodes in comparison to the InfoWorks RS model. For stability reasons, a small time step has to be set for the detailed conceptual model as it contains small floodplain reservoirs. Nevertheless, the conceptual model strongly outperforms the InfoWorks RS model with respect to computational efficiency. The mean absolute error (MAE) of the water level results is limited to $5 \mathrm{~cm}$, with reference to the InfoWorks RS model. When the conceptual model is simplified by stronger lumping, i.e. using reservoirs that span larger areas, the model becomes more stable and the time step can be increased. Together with the reduction in calculation nodes, this results in a model that is 32 times faster than the original detailed conceptual model, while the MAE remains limited to $10 \mathrm{~cm}$. The model reduction approach results in a reduced conceptual model that is an additional ten times faster than the simplified conceptual model. A significant gain in computational efficiency is obtained, while the impact on the model accuracy is negligible. Consequently, using the reduced conceptual model results in a much faster optimization of the future flood control strategy without loss in control quality.

\subsection{Prediction accuracy}

This section investigates the effect of the data assimilation methods described in Section 3 on the prediction accuracy of the prediction model (reduced conceptual model) towards the simulation model (detailed conceptual model). For this, closed-loop simulations are carried out for each of the ten calibration and validation events with a data assimilation frequency equal to $15 \mathrm{~min}$. This means that every $15 \mathrm{~min}$ in the simulation model, the prediction model is updated and a new prediction is carried out for the next $48 \mathrm{~h}$. This new prediction takes the current (and past) observations into account by means of updated initial conditions after applying a state estimator and/or by means of a prediction error method in a post-processing step. The resulting predictions are compared with the corresponding observations in the simulation model and are evaluated based on the MAE, which is the absolute error between predictions and observations averaged over all observed locations and predictions.

\subsubsection{State estimators}

Both the EnKF and the MHE have several tuning parameters to tailor these state estimators for a specific case study. The optimal parameter settings for the Herk case study are determined by means of a sensitivity study according to the one at the time principle. The results shown hereafter are obtained with these optimal parameter settings.

Fig. 7 shows the MAE of the water level predictions as a function of the lead time for different state estimators. The DA methods IU and TIU both reduce the initial error at observed locations to zero. For lead times $>2 \mathrm{~h}$, there is no significant reduction of the MAE in comparison to the situation without state estimator. The EnKF and the MHE have a smaller effect on the initial error, but the effect lasts longer than with TIU. This effect is, however, limited in magnitude. In general, the effect of a state estimator is limited in time. For small lead times the error is reduced, while for larger lead times the error converges back to its original value without state estimator (no SE).

IU and TIU have a negligible computation time as they only require the conversion from the observed water level to the corresponding reservoir volume by means of the hypsometric curve. The MHE and the

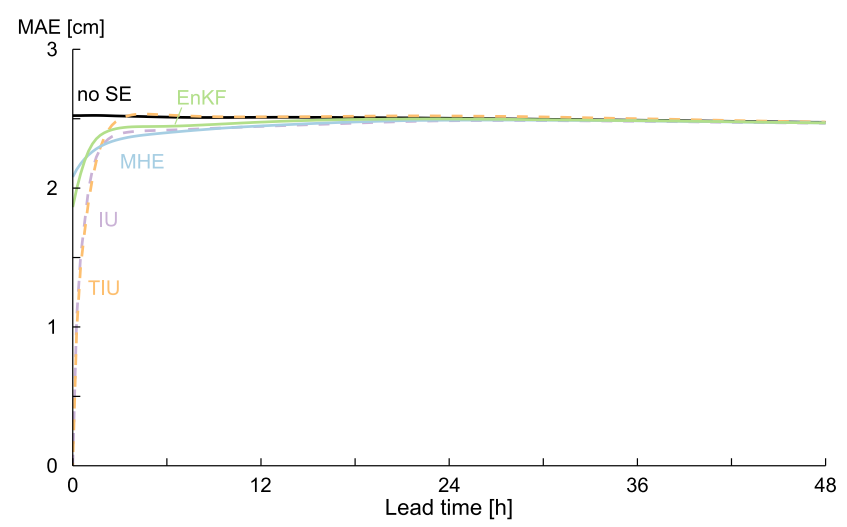

Fig. 7. Comparison of the mean absolute error (MAE) of the water level predictions as a function of the lead time for different state estimators in comparison to the situation without state estimator (no SE). (For the color version of this figure, the reader is referred to the web version of this article.). 


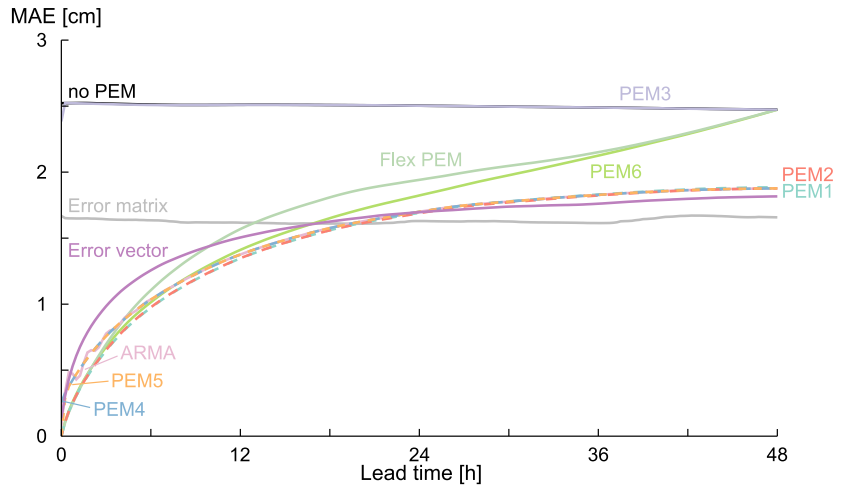

Fig. 8. Comparison of the mean absolute error (MAE) of the water level predictions as a function of the lead time for different prediction error methods in comparison to the situation without prediction error method (no PEM). (For the color version of this figure, the reader is referred to the web version of this article.).

EnKF, however, require a hindcast simulation. The hindcast period of the EnKF is equal to the time between two observations, i.e. $15 \mathrm{~min}$. The hindcast period of the MHE was set equal to $2 \mathrm{~h}$ after a sensitivity study. The longer hindcast period and the fact that the MHE actually solves an optimization problem, leads to a much larger computation time for the MHE.

\subsubsection{Prediction error methods}

Fig. 8 summarizes the obtained results for closed-loop simulations after applying only a prediction error method. As no state estimator is applied in this analysis, the initial conditions for the predictions are copied from the previous prediction without error correction. The applied hindcast period depends on the considered PEM. For PEM1, only the current error is taken into account, while the error matrix approach requires a hindcast period of $48 \mathrm{~h}$. For all other PEMs, a hindcast period of $2 \mathrm{~h}$ was determined by means of a sensitivity analysis.

Real-time control applications typically consider a future time horizon based on a moving window (Barjas-Blanco et al., 2010, Galelli et al., 2014, Tian et al., 2015). Higher importance is given to the model accuracy at short lead times as the control strategy at larger lead times can still be adjusted when the control moves over time. Hence, the best PEM is the one that reduces the prediction error to zero at the time of forecast while also reducing the prediction error at larger lead times as much as possible. From Fig. 8 it can be seen that PEM1 and PEM2 fulfill these criteria best. The error matrix and error vector approach perform better for larger lead times, but worse for small lead times. Also PEM4, PEM5 and ARMA perform worse for small lead times, but similar for larger lead times. PEM6 and Flex PEM reduce the initial error to zero, but they perform worse for larger lead times, converging back to the situation without PEM.

\subsubsection{State estimators and prediction error methods}

This section combines the two most promising PEMs, PEM1 and PEM2, with a state estimator to further improve the prediction accuracy. PEM2 requires a hindcast period of $2 \mathrm{~h}$ and is therefore combined with the MHE. As the hindcast period of the EnKF is limited to $15 \mathrm{~min}$, this state estimator is combined with PEM1, which requires only information about the current error. Updating based on IU and TIU methods cannot be combined with a prediction error method as they do not have a hindcast period and the initial error is already reduced to zero by the state estimator itself.

Fig. 9 summarizes the results for the EnKF and the MHE, with and without PEM. The extension of the data assimilation with a PEM shows a great improvement over data assimilation when considering only a state estimator. Not only is the initial error reduced to zero, also the prediction errors at larger lead times are reduced. When comparing

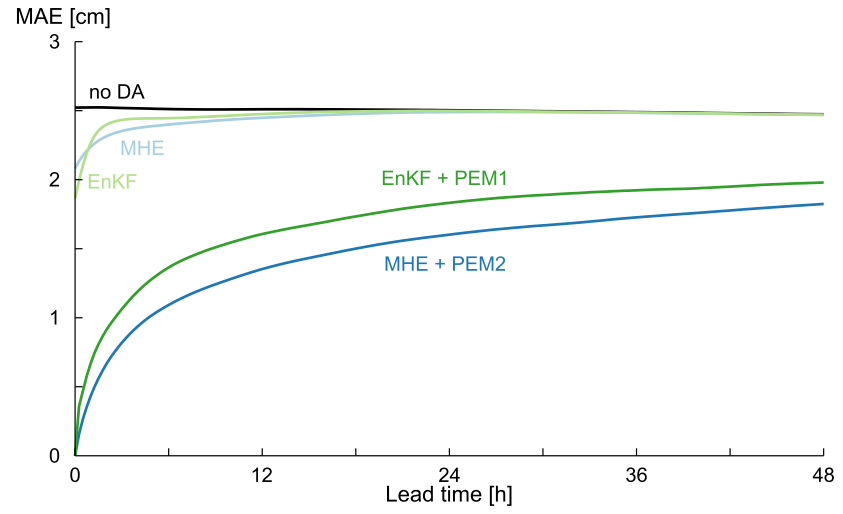

Fig. 9. Comparison of the mean absolute error (MAE) of the water level predictions as a function of the lead time for the ensemble Kalman filter (EnKF) and the moving horizon estimator (MHE) with and without prediction error method (PEM) in comparison to the situation without data assimilation (no DA). (For the color version of this figure, the reader is referred to the web version of this article.).

these results with those of Fig. 7, it is clear that these combined data assimilation approaches also outperform the IU and TIU updating methods.

Because the combination MHE + PEM2 outperforms the combination EnKF + PEM1, it can be concluded that MHE + PEM2 is the appropriate method to improve the prediction accuracy. The drawback of this approach is, however, the higher computation time. Therefore, and because the performance of both combinations, MHE + PEM2 and EnKF + PEM1, is similar, both data assimilation methods are implemented in the model predictive control system to investigate their effect on the real-time control performance.

\subsection{Real-time control performance}

Fig. 10 shows the performance improvement of eight DA methods averaged over the five damage relevant events for the Herk case study (E1, E6, E7, E8 and E10). Also the absolute damage cost reduction is shown for each DA method on the right hand side of the figure, summed over all five events. This is the amount of damage that is avoided by applying the DA method in comparison to the situation without data assimilation (no DA).

Combining the MHE or the EnKF with respectively PEM2 and PEM1 results in an improved control performance. The control performance of these combined DA methods is better than that of IU, but worse than that of TIU. Combining the MHE and EnKF with the flexible prediction error method (Flex PEM) results in the best control performance. Also

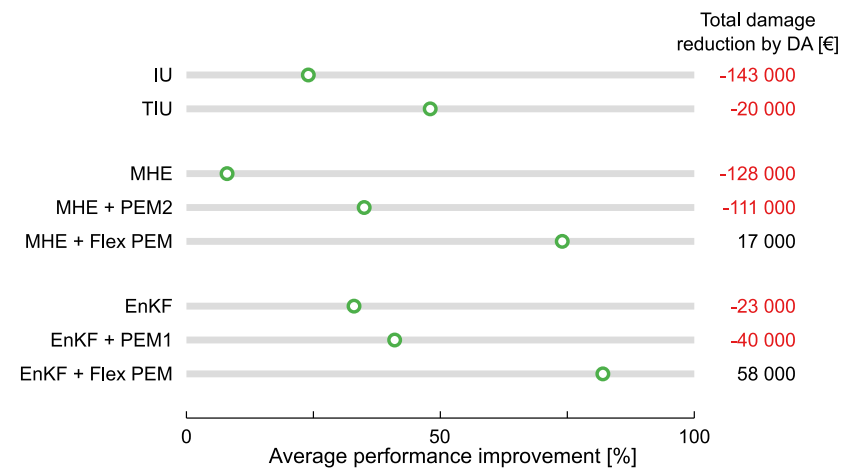

Fig. 10. Average performance improvement for eight different DA methods, together with the summed total damage cost reduction by the DA method, for the five damage relevant events for the Herk case study. 
for each individual event, the best performance is obtained with the flexible DA methods.

PEM1 and PEM2 were clearly the best prediction error methods with respect to the prediction accuracy of the water levels at observed locations when considering both dry and wet periods (see section 4.2.2 and Fig. 8). The proposed flexible prediction error method, however, outperforms these two PEMs with respect to the control performance. This can be explained by the more sophisticated approach of Flex PEM in which the hindcast error is considered in a more detailed way and depending on the situation an appropriate PEM is applied. As a result, Flex PEM performs better during flood relevant moments, i.e. during periods of high water. As these periods determine the final control performance, rather than the low water periods, Flex PEM is preferred to be used for real-time flood control applications.

All DA methods except those with the Flex PEM have a negative total damage cost reduction. This means that the damage cost is higher when applying these DA methods in comparison with MPC optimization without considering feedback from observations. This originates from a bad control performance of these DA methods for event E8, which is the most extreme event. As this event results in the highest damage costs, this has a large impact on the total damage cost reduction. These unsatisfactory results for event E8 can be explained by a badly calibrated broad crested weir in the detailed conceptual model, located in the river reach of the Kleine Herk downstream of the retention basin of Stevoort. During periods of high water, this broad crested weir has a lower flow capacity than the corresponding structures in the reduced conceptual model and the InfoWorks RS model. This difference induces large prediction errors in the reservoir between this broad crested weir and the retention basin during periods of flooding. As this reservoir corresponds to the most damage prone location in the Herk case study, these prediction errors have an important impact on the control performance. More specifically, the prediction model wrongly predicts a decrease of the water level in the concerning reservoir, while actually the corresponding observed water level increases in the simulation model. Accordingly, MPC does not identify this increase in future damage cost and does not anticipate on it. The state estimators correct the initial errors, but afterwards again different water level results are obtained in the simulation model (increasing) and the prediction model (decreasing). PEM1 and PEM2 are not sophisticated enough to identify these diverging results and take this into account during the error correction. Therefore, the flexible prediction error method (Flex PEM) was developed in this study, which can cope with this type of conditions. The Flex PEM shows a significant improvement for event E8 in comparison to PEM1 and PEM2. In combination with the EnKF, a performance improvement of $20 \%$ is achieved towards MPC without data assimilation. A performance improvement close to $100 \%$ is hard to reach, as it requires some time to detect and identify the diverging results, hence before an appropriate error correction can be made. During this time period, which has a length in the order of magnitude of the hindcast period, non-optimal control actions are most probably taken, which of course decreases the final control performance. Therefore, it is important to limit the length of the hindcast period. After analyzing the results, it was concluded that the two hour hindcast period used in this study is appropriate. A shorter hindcast period would make Flex PEM too reactive to hindcast trends, while with a longer hindcast period it would take longer before a diverging trend is detected. In combination with the MHE, the control performance is still worse than that of MPC without data assimilation. This can be explained by the fact that the badly calibrated broad crested weir is a vital component of the conceptual model as it is a hydraulic structure located in one of the main river reaches. These kind of model errors, with an impact of this magnitude, should already be eliminated in the calibration and validation process of the conceptual model, rather than being corrected by means of data assimilation. This modelling error, however, did not manifest during model calibration simulations where no MPC based control was applied but a traditional PLC regulation. Only for the extreme event E8 in combination with the corresponding MPC regulation, this modelling error revealed. Therefore, it is important and advised to also validate conceptual models for regulations different than the PLC based regulation, as is done in Vermuyten et al. (2018). After recalibration of the broad crested weir, the detailed conceptual model shows similar performance as the reduced conceptual model and the InfoWorks RS model for event E8. The authors, however, decided to continue with the original weir implementation, since it is interesting to see how the flexible prediction error method succeeds in strongly reducing the negative impact of this modelling error.

\subsection{Magnitude of the model uncertainty}

It has to be noted that in real-life cases the total model uncertainties may be larger than the ones considered in this study. As can be seen from Fig. 7, the average prediction error is in this study limited to $3 \mathrm{~cm}$. Minor model errors can thus have a large effect on the final control performance. Moreover, improved water level predictions at observed locations do not necessarily lead to improved predictions of the surrounding water levels and of the control objectives. The water level observations are, however, the only available feedback information. Minimizing the prediction errors at the observed locations is the best one can do and the only way to take model uncertainties into account. It is much more difficult to improve the control performance in case of small model uncertainties than in case of large model uncertainties. Fig. 11 demonstrates this by means of a conceptual drawing.

In case of small model uncertainties (small observed error, orange triangles), data assimilation (DA) can possibly result in a corrected prediction (green squares) that is worse than the prior prediction when evaluated over all modeled water level nodes. In this case, data assimilation deteriorates the overall prediction accuracy. On the other hand, in case of large model uncertainties (large observed error, red circles), DA will more easily and clearly improve the overall prediction accuracy. The final prediction accuracy of the corrected prediction is in both cases, however, the same.

As this paper investigates the effect of different DA methods on the real-time control performance for a case study with limited model uncertainty, the results may be influenced by small modelling errors as it is more difficult to obtain large performance improvements in such cases. Despite this difficulty, the flexible data assimilation approach presented in this work turns out to be a promising technique to account for hydrodynamic model uncertainty. It is, however, recommended to conduct further research in which larger model uncertainties are

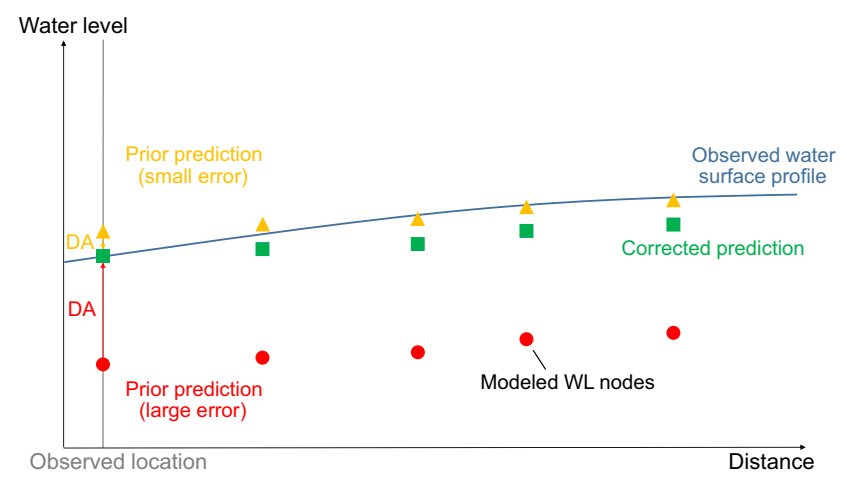

Fig. 11. Conceptual drawing. Prediction of five water level (WL) nodes in one reservoir for two cases, one with a small error at the observed location (orange triangles) and one with a large error (red circles), together with the corrected prediction after data assimilation (DA) (green squares) and the observed water surface profile. (For interpretation of the references to color in this figure legend, the reader is referred to the web version of this article.). (For interpretation of the references to color in this figure legend, the reader is referred to the web version of this article.) 
considered to further investigate the benefits of the flexible data assimilation approach.

\section{Conclusions}

A new conceptual model type is presented in this paper: reduced conceptual models. These models are specially tailored to real-time flood control and optimization applications by eliminating unnecessary variables and intermediate calculations from simplified conceptual models. In addition, hydraulic structures are grouped and replaced by flow matrices. This reduction process hardly affects the model accuracy, while a significant gain in computational efficiency is obtained. The reduced conceptual model of the Herk river is ten times faster than the corresponding simplified conceptual model. Due to the model reduction process, detailed simulation results are not provided by a reduced conceptual model. They, however, still provide the control objectives, which makes them perfectly suitable for real-time flood control optimization problems.

The proposed RGA-MPC method makes uses of the reduced conceptual model to predict the future states of the river system. These predictions are, however, subject to model mismatches between this river model and the actual river system. This paper investigated the effect of the hydrodynamic model uncertainty on the real-time control performance by using the reduced conceptual model for the optimization process (prediction model) and the detailed conceptual model to represent the actual river system (simulation model). The same rainfall forecasts were used in both models, assuming perfect rainfall forecasts. The effect of the rainfall forecast uncertainty will be investigated in future work.

In order to take model uncertainty into account and improve the prediction accuracy, the prediction model is extended with data assimilation techniques. State estimators and prediction error methods were first tested with respect to the prediction accuracy. State estimators have only a limited effect over time. They improve the initial error at the time of forecast, but for larger lead times, the error converges back to the situation without state estimator. Prediction error methods have a larger impact on the prediction accuracy. PEM1 and PEM2, proposed by Van Steenbergen et al. (2013), were selected as the best prediction error methods as they reduce the error at the time of forecast to zero and also strongly reduce the errors at larger lead times. A data assimilation approach combining a state estimator and a prediction error method is recommended as this results in the best prediction accuracy.

The reduced genetic algorithm is extended with a state estimator and a prediction error method to investigate the effect of model uncertainty on the real-time control performance for the Herk case study. The implemented DA approaches showed clear benefits and strongly reduced the loss in performance due to model uncertainty for all events except event E8. Due to a badly calibrated broad crested weir in one of the main streams of the network, strong prediction errors occurred for this event. PEM1 and PEM2 were not sophisticated enough to detect the diverging trend between predictions and observations. Therefore, a new prediction error method was proposed, the flexible prediction error method (Flex PEM). This approach analyzes the past model residuals and depending on the observed trend, an appropriate prediction error model is applied. By doing so, the control performance was strongly increased for this event. Also for all other events, the combination of the moving horizon estimator or the ensemble Kalman filter with this flexible prediction error method outperformed all other data assimilation methods. Flex PEM outperforms PEM1 and PEM2 with respect to the control performance as this PEM performs better during periods of high water, hence during periods which are of importance for the incurred flood damage cost.

The conclusions made in this study are based on an experimental set-up with only limited model uncertainty and a small river system. It is recommended to further investigate the applicability and benefits of the flexible prediction error method by considering additional case studies with larger model uncertainty and larger river systems in future work. Nevertheless, it can be concluded that the flexible data assimilation approach presented in this paper is a promising technique as it outperforms other data assimilation methods in the challenging case of small hydrodynamic model uncertainties.

\section{Acknowledgments}

This research was supported by a $\mathrm{PhD}$ scholarship granted by the Agency for Innovation by Science and Technology in Flanders. The authors would like to thank Innovyze for the InfoWorks RS software license, and the Flemish Environment Agency (VMM) for the data and InfoWorks RS model of the Herk river. The International Marine and Dredging Consultants derived the damage-stage relations for the different floodplains along the river network, as part of a project by the Tijdelijke Handelsvereniging Antea Group, Fabricom, IMDC and IPCOS (THV AFII) for VMM.

\section{References}

Barjas-Blanco, T., Chiang, P., Breckpot, M., Willems, P., Berlamont, J., De Moor, B., 2010. Flood regulation using nonlinear model predictive control. Control Eng. Prac. 18 (10), 1147-1157. https://doi.org/10.1016/j.conengprac.2010.06.005.

Brandimarte, L., Di Baldassarre, G., 2012. Uncertainty in design flood profiles derived by hydraulic modelling. Hydrol. Res. 43 (6), 753-761. https://doi.org/10.2166/nh. 2011.086.

Breckpot, M., Agudelo, O.M., Meert, P., Willems, P., De Moor, B., 2013. Flood control of the demer by using model predictive control. Control Eng. Pract. 21 (12), 1776-1787. https://doi.org/10.1016/j.conengprac.2013.08.008.

Broersen, P.M.T., 2002. Automatic spectral analysis with time series models. IEEE Trans. Instrum. Meas. 51, 211-216. https://doi.org/10.1109/19.997814.

Broersen, P.M.T., Weerts, A.H., 2005. Automatic error correction of rainfall-runoff models in flood forecasting systems. Proc. IEEE 2, 963-968. https://doi.org/10.1109/IMTC. 2005.1604281.

Chen, F., Crow, W.T., Starks, P.J., Moriasi, D.N., 2011. Improving hydrologic predictions of a catchment model via assimilation of surface soil moisture. Adv. Water Resour. 34 (4), 526-536. https://doi.org/10.1016/j.advwatres.2011.01.011.

Chiang, P., Willems, P., 2015. Combine evolutionary optimization with model predictive control in real-time flood control of a river system. Water Resour. Manage. 29 (8), 2527-2542. https://doi.org/10.1007/s11269-015-0955-5.

De Nicolao, G., Magni, L., Scattolini, R., 1996. On the robustness of receding-horizon control with terminal constraints. IEEE Trans. Autom. Control 41 (3), 451-453. https://doi.org/10.1109/9.486649.

De Vleeschauwer, K., Weustenraad, J., Nolf, C., Wolfs, V., De Meulder, B., Shannon, K., Willems, P., 2014. Green-blue water in the city: quantification of impact of source control versus end-of-pipe solutions on sewer and river floods. Water Sci. Technol. 70 (11), 1825-1837. https://doi.org/10.2166/wst.2014.306.

Delgoda, D.K., Saleem, S.K., Halgamuge, M.N., Malano, H., 2013. Multiple model predictive flood control in regulated river systems with uncertain inflows. Water Resour. Manage. 27, 765-790. https://doi.org/10.1007/s11269-012-0214-y.

EM-DAT: The OFDA/CRED International Disaster Database - www.emdat.be, Université Catholique de Louvain, Brussels (Belgium).

Evensen, G., 1994. Sequential data assimilation with a nonlinear quasi-geostrophic model using Monte Carlo methods to forecast error statistics. J. Geophys. Res. 97, 905-924. https://doi.org/10.1029/94JC00572.

Ficchi, A., Raso, L., Dorchies, A., Pianosi, F., Malaterre, P.O., van Overloop, P.J., JayAllemand, M., 2016. Optimal operation of the multireservoir system in the seine river basin using deterministic and ensemble forecasts. J. Water Resour. Plann. Manage. 142 (1), 05015005. https://doi.org/10.1061/(ASCE)WR.1943-5452.0000571.

Freni, G., Mannina, G., 2010. Uncertainty in water quality modelling: the applicability of variance decomposition approach. J. Hydrol. 394 (3-4), 324-333. https://doi.org/ 10.1016/j.jhydrol.2010.09.006.

Galelli, S., Goedbloed, A., Schwanenberg, D., van Overloop, P.J., 2014. Optimal real-time operation of multipurpose urban reservoirs: case study in Singapore. J. Water Resour. Plann. Manage. 140 (4), 511-523. https://doi.org/10.1061/(ASCE)WR.1943-5452. 0000342.

Gillijns, S., Barrero Mendoza, O., Chandrasekar, J., De Moor, B.L.R., Bernstein, D.S. \& Ridley, A., 2006. What Is the Ensemble Kalman Filter and How Well Does it Work. Proceedings of the 2006 American Control Conference, Minneapolis, Minnesota, USA, June 14-16, 2006, pp. 4448-4453. Doi: 10.1109/ACC.2006.1657419.

Hargreaves, J.C., Annan, J.D., Edwards, N.R., Marsh, R., 2004. An efficient climate forecasting method using an intermediate complexity Earth System Model and the ensemble Kalman filter. Clim. Dyn. 23 (7-8), 745-760. https://doi.org/10.1007/ s00382-004-0471-4.

Haseltine, E.L., Rawlings, B., 2005. Critical evaluation of extended kalman filtering and moving-horizon estimation. Ind. Eng. Chem. Res. 44 (8), 2451-2460. https://doi.org/ 10.1021/ie0343081.

Hawley, R.J., Bledsoe, B.P., 2011. How do flow peaks and durations change in 
suburbanizing semi-arid watersheds? A southern California case study. J. Hydrol. 405, 69-82. https://doi.org/10.1016/j.jhydrol.2011.05.011.

HIC, 2003. De digitale Demer: een nieuw en krachtig instrument voor waterpeilbeheer [The digital Demer: a new and powerful instrument for water level management]. Hydrologic information service of the authorities of Flanders, Borgerhout, Belgium, pp. 28 (in Dutch)

Huang, H.J., Cheng, S.J., Wen, J.C., Lee, J.H., 2008. Effect of growing watershed imperviousness on hydrograph parameters and peak discharge. Hydrol. Process. 22, 2075-2085. https://doi.org/10.1002/hyp.6807.

Hutton, C.J., Vamvakeridou-Lyroudia, L.S., Kapelan, Z. \& Savic, D.A., 2011. Real-time Modelling and Data Assimilation Techniques for Improving the Accuracy of Model Predictions: Scientific report. Prepared: Enabling Change, European Commision 7th Framework Programme. European Commision.

Hutton, C.J., Kapelan, Z., Vamvakeridou-Lyroudia, L.S., Savic, D.A., 2014a. Real-time data assimilation in urban rainfall-runoff models. Proced. Eng. 70, 843-852. https:// doi.org/10.1016/j.proeng.2014.02.092.

Hutton, C.J., Kapelan, Z., Vamvakeridou-Lyroudia, L.S., Savic, D.A., 2014b. Dealing with uncertainty in water distribution system models: a framework for real-time modeling and data assimilation. J. Water Resour. Plann. Manage. 140 (2), 169-183. https:// doi.org/10.1061/(ASCE)WR.1943 5452.0000325.

Innovyze, 2014. InfoWorks RS Help Documentation [Version 14.0], Innovyze, Oxfordshire, UK.

IPCC, 2014. Climate Change 2014: Impacts, Adaptation, and Vulnerability. Summary for Policymakers. Working Group II contribution to the Fifth Assessment Report of the Intergovernmental Panel on Climate Change, pp. 44.

Julier, S.J., Uhlmann, J.K., 2004. Unscented Filtering and Nonlinear Estimation. Proc. IEEE 92 (3), 401-422. https://doi.org/10.1109/JPROC.2003.823141.

Komma, J., Blöschl, G., Reszler, C., 2008. Soil moisture updating by Ensemble Kalman Filtering in real-time flood forecasting. J. Hydrol. 357 (3-4), 228-242. https://doi. $\operatorname{org} / 10.1016 / j . j h y d r o l .2008 .05 .020$.

Lehner, B., Döll, P., Alcamo, J., Henrichs, T., Kaspar, F., 2006. Estimating the impact of global change on flood and drought risks in europe: a continental, integrated analysis. Clim. Change 75, 273-299. https://doi.org/10.1007/s10584 00663384.

Liu, Y., Weerts, A.H., Clark, M., Hendricks Franssen, H.J., Kumar, S., Moradkhani, H., Seo, D.J., Schwanenberg, D., Smith, P., van Dijk, A.I.J.M., van Velzen, N., He, M., Lee, H., Noh, S.J., Rakovec, O., Restrepo, P., 2012. Advancing data assimilation in operational hydrologic forecasting: progresses, challenges, and emerging opportunities. Hydrol. Earth Syst. Sci. 16 (10), 3863-3887. https://doi.org/10.5194/hess-16-3863-2012.

Madsen, H., Skotner, C., 2005. Adaptive state updating in real-time river flow forecasting - a combined filtering and error forecasting procedure. J. Hydrol. 308 (1-4), 302-312. https://doi.org/10.1016/j.jhydrol.2004.10.030.

Magni, L., Sepulchre, R., 1997. Stability margins of nonlinear receding-horizon control via inverse optimality. Syst. Control Lett. 32 (4), 241-245. https://doi.org/10.1016/ S0167-6911(97)00079-0.

Mayne, D.Q., Rawlings, J.B., Rao, C.V., Scokaert, P.O.M., 2000. Constrained model predictive control: Stability and optimality. Automatica 36 (6), 789-814. https://doi. org/10.1016/S0005-1098(99)00214-9.

Meert, P., Pereira, F., Willems, P., 2016. Computationally efficient modelling of tidal rivers using conceptual reservoir-type models. Environ. Modell. Software 77, 19-31. https://doi.org/10.1016/j.envsoft.2015.11.010.

Meert, P., 2017. Conceptual river modelling in support of uncertainty and scenario analyses at catchment scale. PhD thesis, KU Leuven, Faculty of Engineering, Belgium.

Meirlaen, J., Huyghebaert, B., Sforzi, F., Benedetti, L., Vanrolleghem, P.A., 2001. Fast, simultaneous simulation of the integrated urban wastewater system using mechanistic surrogate models. Water Sci. Technol. 47 (7), 301-308.

Millennium Ecosystem Assessment, 2005. Ecosystems and Human Well-being: Synthesis. Island Press, Washington, DC.

MIRA, 2013. Milieurapport Vlaanderen: Indicatorrapport 2012. Marleen Van Steertegem (Ed.), Milieurapport Vlaanderen, Vlaamse Milieumaatschappij. Raadpleegbaar op www.milieurapport.be. (in Dutch).

Moradkhani, H., Sorooshian, S., Gupta, H.V., Houser, P.R., 2005. Dual state-parameter estimation of hydrological models using ensemble Kalman filter. Adv. Water Resour. 28 (2), 135-147. https://doi.org/10.1016/j.advwatres.2004.09.002.

Naevdal, G., Johnsen, L., Aanonsen, S., Vefring, E., 2003. Reservoir Monitoring and Continuous Model Updating using Ensemble Kalman Filter. SPE J. 10, 66-74. https:// doi.org/10.2118/84372-PA.

Poelmans, L., Van Rompaey, A., Ntegeka, V., Willems, P., 2011. The relative impact of climate change and urban expansion on river flows: a case study in central Belgium. Hydrol. Process. 25 (18), 2846-2858. https://doi.org/10.1002/hyp.8047.
Raso, L., Schwanenberg, D., van den Giesen, N.C., van Overloop, P.J., 2014. Short-term optimal operation of water systems using ensemble forecasts. Adv. Water Resour. 71, 200-208. https://doi.org/10.1016/j.advwatres.2014.06.009.

Rawlings, J.B., Bakshi, B.R., 2006. Particle filtering and moving horizon estimation. Comput. Chem. Eng. 30, 1529-1541. https://doi.org/10.1016/j.compchemeng.2006. 05.031.

Refsgaard, J.C., van der Sluijs, J.P., Højberg, A.L., Vanrolleghem, P.A., 2007. Uncertainty in the environmental modelling process - A framework and guidance. Environ. Modell. Software 22 (11), 1543-1556. https://doi.org/10.1016/j.envsoft.2007.02. 004.

Sarma, P., Durlofsky, L.J., Aziz, K., Chen, W.H., 2006. Efficient real-time reservoir management using adjoint-based optimal control and model updating. Comput. Geosci. 10, 3-36. https://doi.org/10.1007/s10596-005-9009-z.

Schwanenberg, D., Xu, M., Ochterbeck, T., Allen, C., Karimanzira, D., 2014. Short-term management of hydropower assets of the Federal Columbia River power system. J. Appl. Water Eng. Res. 2 (1), 25-32. https://doi.org/10.1080/23249676.2014. 912952.

Shrestha, D.L., Solomatine, D.P., 2008. Data-driven approaches for estimating uncertainty in rainfall-runoff modelling. Int. J. River Basin Manage. 6 (2), 109-122. https://doi. org $/ 10.1080 / 15715124.2008 .9635341$.

Tian, X., van Overloop, P.J., Negenborn, R.R., van de Giesen, N., 2015. Operational flood control of a low-lying delta system using large time step model predictive control. Adv. Water Resour. 75, 1-13. https://doi.org/10.1016/j.advwatres.2014.10.010.

Van Overloop, P.J., Weijs, S., Dijkstra, S., 2008. Multiple Model Predictive Control on a drainage canal system. Control Eng. Pract. 16, 531-540. https://doi.org/10.1016/j. conengprac.2007.06.002.

Van Steenbergen, N., Deschamps, M., Willems, P., Boeckx, L. \& Mostaert, F., 2013. Bijstand voorspellingen: deelrapport 3 - Onzekerheid bij overstromingsvoorspellingen: decompositie en reductie. Versie 2_0. Rapport, 00_123. Waterbouwkundig Laboratorium \& KU Leuven: Antwerpen, België. (in Dutch).

Vanrolleghem, P.A., Benedetti, L., Meirlaen, J., 2005. Modelling and real-time control of the integrated urban wastewater system. Environ. Modell. Software 20, 427-442. https://doi.org/10.1016/j.envsoft.2004.02.004.

Vansteenkiste, T., Tavakoli, T., Ntegeka, V., De Smedt, F., Batelaan, O., Pereira, F., Willems, P., 2014. Intercomparison of hydrological model structures and calibration approaches in climate scenario impact projections. J. Hydrol. 519, 743-755. https:// doi.org/10.1016/j.jhydrol.2014.07.062.

Vermuyten, E., Meert, P., Wolfs, V., Willems, P., 2018. Combining model predictive control with a reduced genetic algorithm for real-time flood control. J. Water Resour. Plann. Manage. 144 (2), 04017083. https://doi.org/10.1061/(ASCE)WR.1943-5452. 0000859.

Walker, W.E., Harremoës, P., Rotmans, J., van der Sluijs, J.P., Van Asselt, M.B.A., Janssen, P., Krayer von Krauss, M.P., 2003. Defining uncertainty: a conceptual basis for uncertainty management in model-based decision support. Integr. Assess. 4 (1), 5-17. https://doi.org/10.1076/iaij.4.1.5.16466.

Wen, X.H., Chen, W.H., 2005. Real-Time Reservoir Model Updating Using Ensemble Kalman Filter. SPE Reservoir Simulation Symposium, The Woodlands, Texas, USA, January 31 - February 2, 2005. doi: 10.2118/92991-MS.

Whittle, P., 1951. Hypothesis testing in times series analysis. Almqvist \& Wiksells Boktryckeri AB, Uppsala.

Willems, P., Olsson, J., Arnbjerg-Nielsen, K., Beecham, S., Pathirana, A., Bülow Gregersen, I., Madsen, H., Nguyen, V.T.V., 2012. Impacts of Climate Change on Rainfall Extremes and Urban Drainage Systems. IWA Publishing, 252 p., Paperback Print ISBN 9781780401256; Ebook ISBN 9781780401263.

Willems, P., 2012. Model uncertainty analysis by variance decomposition. Phys. Chem. Earth 42-44, 21-30 org/10.1016/j.pce.2011.07.003.

Wolfs, V., Van Steenbergen, N. Willems, P., 2012. Flood probability mapping by means of conceptual modeling. In: Muñoz, R. (Ed.), River Flow 2012, International Conference on Fluvial Hydraulics, Costa Rica, 5-7 Sept. 2012, vol. 2. CRC Press, Taylor \& Francis Group, London, pp. 1081-1085.

Wolfs, V., Meert, P., Willems, P., 2015. Modular conceptual modelling approach and software for river hydraulic simulations. Environ. Modell. Software 71, 60-77. https://doi.org/10.1016/j.envsoft.2015.05.010.

Wolfs, V., Tran Quoc, Q., Willems, P., 2016. A flexible and efficient multi-model framework in support of water management. Proc. IAHS 373, 1-6. https://doi.org/10. 5194/piahs-373-1-2016.

Xie, X., Zhang, D., 2010. Data assimilation for distributed hydrological catchment modeling via ensemble Kalman filter. Adv. Water Resour. 33 (6), 678-690. https://doi. org/10.1016/j.advwatres.2010.03.012. 